\title{
Spectral Analysis of Moderately Charged Rare-Gas Atoms
}

\author{
Jorge Reyna Almandos * and Mónica Raineri \\ Centro de Investigaciones Ópticas, M. B. Gonnet, P.O. Box 3 (1897), La Plata 20646, Argentina; \\ monicar@ciop.unlp.edu.ar \\ * Correspondence: jreyna@ciop.unlp.edu.ar; Tel.: +54-221-484-2957
}

Academic Editor: Joseph Reader

Received: 27 December 2016; Accepted: 21 February 2017; Published: 7 March 2017

\begin{abstract}
This article presents a review concerning the spectral analysis of several ions of neon, argon, krypton and xenon, with impact on laser studies and astrophysics that were mainly carried out in our collaborative groups between Argentina and Brazil during many years. The spectra were recorded from the vacuum ultraviolet to infrared regions using pulsed discharges. Semi-empirical approaches with relativistic Hartree-Fock and Dirac-Fock calculations were also included in these investigations. The spectral analysis produced new classified lines and energy levels. Lifetimes and oscillator strengths were also calculated.
\end{abstract}

Keywords: atomic spectra; energy levels; relativistic Hartree-Fock calculations

\section{Introduction}

There is great interest in spectroscopy data from rare gases due to applications in collision physics, fusion diagnostics, photo-electron spectroscopy, astrophysics, and to help understanding laser emission mechanisms. Information on wavelengths and intensities of the spectral lines and energy levels of moderately charged rare-gas atoms is important for these studies. Many processes must be considered in few times ionized atoms related with the widths and shapes of the spectral lines due to the presence of electric and magnetic fields. New spectral analysis of the $\mathrm{p}^{2}, \mathrm{p}^{3}, \mathrm{p}^{4}$ configurations of moderately ionized noble gases provide us with relevant information to understand the behavior of the atomic parameters in the intermediate type of coupling, when neither a pure electrostatic nor spin-orbit scheme exists.

In plasma physics, the radiative properties of atoms and ions are important for temperature determination and to calculate the concentrations of different plasma components. In the development of future tokamaks, damage by excessive heat load on the plasma-facing components is a major problem. In the ITER (International Thermonuclear Experimental Reactor) Tokamak, injection of krypton has been proposed to produce a peripheral radiating mantle that spreads the heat load, cooling the outermost plasma region and reducing erosion. In the plasma edge and in the divertor region, electron energy ranges from a few to about $100 \mathrm{eV}$ corresponding to $\mathrm{Kr}$ I to $\mathrm{Kr}$ VIII spectra.

In astrophysics, the spectra of lower stages of ionization are found in space in nebulae, interstellar clouds, chemically peculiar stars, and in the sun. Several atomic parameters, such as energy levels, oscillator strengths, transition probabilities, and radiative lifetimes are important to determine many features of cosmic objects such as element abundance and electronic temperature. Transition probabilities are also needed to calculate the energy transport through the star in model atmospheres.

In this article, a comprehensive review is presented concerning the spectral analysis of several ions of neon, argon, krypton, and xenon, with deep and extended implications for astrophysical and laser studies that were mainly carried out in our collaborative groups between Argentina and Brazil 
over many years. Using pulsed discharges, the spectra were recorded from the vacuum ultraviolet (VUV) to infrared regions. Semi-empirical approaches with relativistic Hartree-Fock (HFR) and multi-configurational Dirac-Fock (MCDF) calculations were used in the studies. A great number of new energy levels and classified lines were established, along with lifetimes and weighted oscillator strengths being reported in local and international meetings, distributed through internal reports, and published elsewhere. Regularities and systematic trends from the atomic structure were also used for the interpretation of the spectra.

\section{Brief History}

At the beginning of the 1960s, the activities related with Atomic Spectroscopy carried on by some of the present members of the Centro de Investigaciones Opticas (CIOp), were centered on the measuring by interferometric methods of secondary standards in the thorium 232 wavelength. These works were done at the Physics Department of the Universidad Nacional de La Plata, under the direction of Athos Giacchetti [1].

From 1964, with the laser already known, research orientation was directed to subjects that can be defined as spectroscopy of the laser. The first works on this new field were made abroad, thanks to fellowships granted to the group members (currently M. Garavaglia, M. Gallardo and C.A. Massone) by the Swedish government. They dealt with noble gases and molecular nitrogen lasers. These works included the spectroscopy study of the emitted radiation, lines assignment, and the analysis of the excitation mechanisms of laser transitions [2-7].

When CIOp was constituted in 1977, investigations of noble gases were centered on studies about the spontaneous and laser spectroscopy of xenon. A pulsed electrical discharge tube was employed in two ways: as generator of stimulated emission in the blue-green and secondly in spontaneous emission developing very rich-in-lines spectra of the first ions of the gas $[8,9]$.

In 1985, A. G. Trigueiros, from Brazil, and J. Reyna Almandos made their postdoctoral studies at the Lund Institute of Technology, Sweden, under the direction of Willy Persson. They were working on the atomic emission spectroscopy of moderately rare gas ions, in particular in obtaining krypton spectra in the VUV region using a $\theta$-pinch as a spectral light source. Using these data an extended spectral analysis of the $4 \mathrm{~s}^{2}, 4 \mathrm{~s} 4 \mathrm{~d}, 4 \mathrm{p}^{2}$, and $4 \mathrm{~s} 4 \mathrm{p}$ configurations in Zn-like six times ionized krypton was completed [10]. The interest in data belonging to this isoelectronic sequence is due to observations of impurity-lines from highly ionized heavy ions with few valence electrons in high temperature plasmas in which such lines have been used for diagnostic purposes. In particular, the resonant transition $4 \mathrm{~s}^{21} \mathrm{~S}_{0}-4 \mathrm{~s} 4 \mathrm{p}{ }^{1} \mathrm{P}_{1}$ has been observed for a large range of $\mathrm{Z}$ values in the $\mathrm{Zn} \mathrm{I}$ isoelectronic sequence.

Since 1986, when A.G.T. returned to the University of Campinas (UNICAMP), Brazil and J.R.A. to CIOp, Argentina, a strong collaboration began on the spectral studies of noble gases that involved both groups. At this point, it is important to mention the support provided to these first activities was given by W. Persson and I. Martinson from the University of Lund, Sweden, which included the donation of one spectrograph for work in the VUV region to the CIOp and two to the UNICAMP. With this equipment, it was possible to extend the spectral range for our studies and new and extended analysis of different ions of $\mathrm{Kr}, \mathrm{Xe}, \mathrm{Ar}$, and Ne were carried out; some examples of these results were reported in [11-16] (and references therein).

\section{Experimental Methods}

We have used two different light sources in our experiments, a pulsed electrical discharge tube and a $\theta$-pinch discharge.

The pulsed discharge tube was built at CIOp [16]. This light source consists of a Pyrex tube $100 \mathrm{~cm}$ in length and with an inner diameter $0.5 \mathrm{~cm}$ in which the gas excitation is produced by discharging a bank of low-inductance capacitors ranging from 20 to $280 \mathrm{nF}$, charged with voltages up to $20 \mathrm{kV}$. The schematic of the electric circuit is shown in Figure 1. 


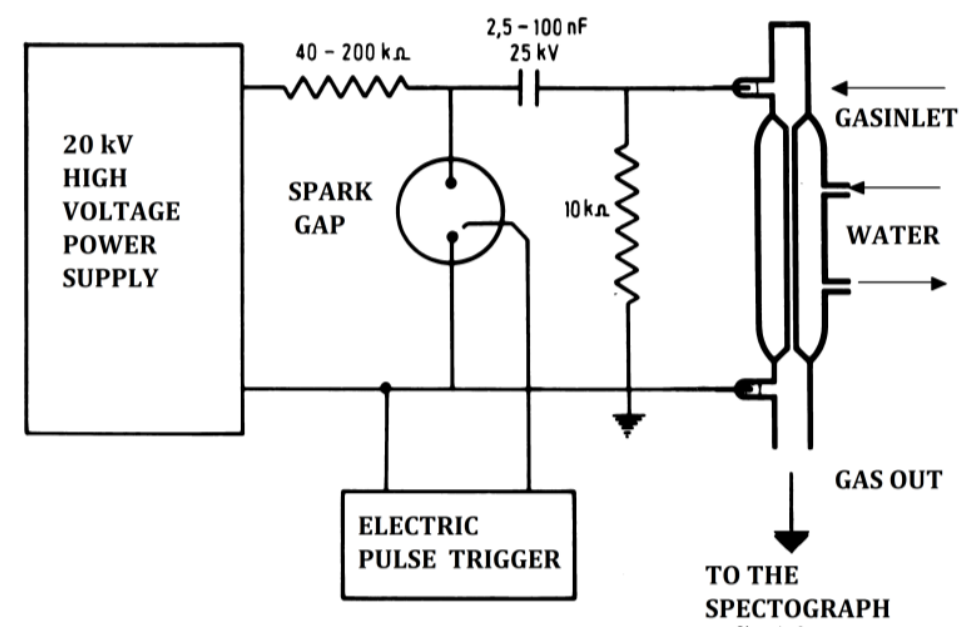

Figure 1. Schematic of the electric circuit. Reproduced and modified by permission of IOP Publishing from [16]. (@ The Royal Swedish Academy of Sciences. All rights reserved.)

The second experiment was performed using a $\theta$-pinch discharge built at the Department of Physics, UNICAMP, where the energy was also fed into the plasma using a capacitor bank of $7.7 \mu \mathrm{F}$, charged from a high-voltage power supply. A discharge tube with a length of $100 \mathrm{~cm}$ and an outside diameter of $8 \mathrm{~cm}$ was used. Figure 2 shows a schematic of the electric circuit and more details of the experiment can be found in Ref. [17].

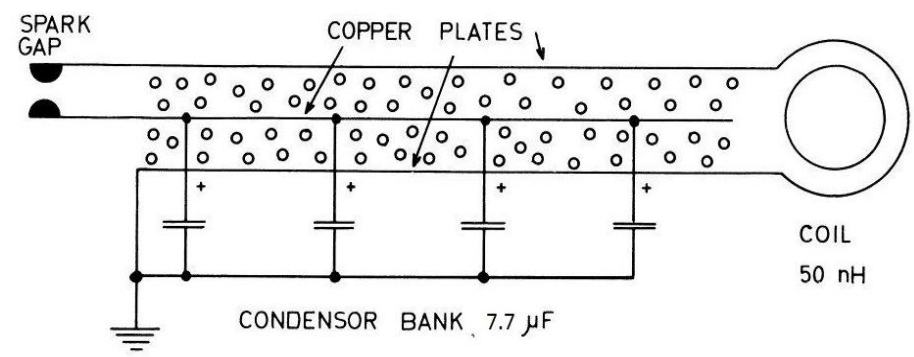

OOOO INSULATION

Figure 2. Schematic of the $\theta$-pinch electric circuit. Reproduced and modified by permission of IOP Publishing from [18]. (๑ The Royal Swedish Academy of Sciences. All rights reserved.)

The wavelength range above $2000 \AA$ was observed in La Plata using a diode array detector coupled to the $3.4 \mathrm{~m}$ Ebert plane-grating spectrograph with 600 lines $/ \mathrm{mm}$ and a plate factor of $5 \AA / \mathrm{mm}$ in the first diffraction order. Photographic plates were used to record the spectra in the first, second, and third diffraction orders. The spectral lines observed were compared with interferometrically measured ${ }^{232} \mathrm{Th}$ wavelengths [19] and with known lines of noble gas spectra. The positions of spectral lines were determined by means of a rotating prism photoelectric semiautomatic Grant comparator. For sharp lines, the settings are reproducible to within $\pm 1 \mu \mathrm{m}$. A third-order interpolation formula was used to reduce comparator settings to wavelength values. Most of the spectral lines from this region used in the analysis were recorded in the third diffraction order. The accuracy of the thorium standard wavelength values used was on the order of $0.005 \AA$, and the determination of the overall wavelength values of lines presented in this work was estimated to be correct to $\pm 0.01 \AA$.

In the wavelength range below $2100 \AA$ light radiation emitted axially was analyzed using a $3 \mathrm{~m}$ normal incidence vacuum spectrograph with a concave diffraction grating of 1200 lines mm $\mathrm{mm}^{-1}$ and a plate factor in the first order of $2.77 \AA \mathrm{mm}^{-1}$. Kodak SWR and Ilford Q plates were used to record 
the spectra. $\mathrm{C}, \mathrm{N}, \mathrm{O}$, and known lines of noble gas spectra served as internal wavelength standards. The uncertainty of the wavelength below $2100 \AA$ was estimated to be $\pm 0.02 \AA$. By observing the behavior of the spectral line intensity as a function of pressure and discharge voltage, we were able to distinguish the different ionic states of spectra.

Energy level values derived from the observed lines were determined by means of an iterative procedure that takes into account the wave numbers of the lines, weighted by their estimated uncertainties. The uncertainty of the adjusted experimental energy level values was assumed to be lower than $2 \mathrm{~cm}^{-1}$.

With the above mentioned experimental devices, it was possible to record the spectra of Ne II-VII, Ar II-VIII, Kr II-VIII, and Xe II-IX in the region between 250 and $7000 \AA$ A.

\section{Atomic Calculations}

Calculation of energy levels and transition probability in different spectral analysis has been carried out using the HFR approach [20]. Weighted oscillator strengths (gf), weighted transition probabilities (gA), and lifetimes were done for the experimentally known dipole transition and levels. Values were determined by using the Hartree-Fock method, including relativistic corrections and core-polarization effects with electrostatic parameters optimized by a least squares procedure in order to obtain energy levels adjusted to the corresponding experimental values in which core polarization refers to the deformation of the internal atomic orbitals due to the orbit of the active electron, which repels the remaining electrons [21]. In our work, we modified the electric dipole matrix elements to take core polarization effects into account. Other extensive calculation and studies on noble gas ions including this effect were also carried out by Biémont and co-workers [22-25]. In this last case, all the radial wave functions were also modified by a model potential, including one- and two-body core-polarization contributions, together with a core-penetration correction. In some of our studies, the fully relativistic MCDF approach was also used, more precisely the general-purpose relativistic atomic structure package (GRASP) [26]. These computations were done with an extended average level (EAL) option.

\section{Previous Works and Laser Studies}

The spectral analysis of moderately charged rare-gas atoms has been carried out in our groups for many years. Studies on line shifts of Xe II, Xe III, Kr II, and Kr III in high current pinched discharges were also conducted. These shifts were observed when comparing the experimental values obtained through the pulsed discharge tube with those coming from a different kind of discharge [27]. By using a simple collision model, it was possible to show that these shifts may be attributed to the microscopic Stark effect $[28,29]$.

Low-pressure xenon plasma excited by pulsed high-current-high-voltage electrical discharges produces high-gain laser transitions in the near UV and visible. Thus, knowledge of the spectral analysis corresponding to different involved ions, is necessary to understand the population mechanisms responsible for most of the classified laser xenon transitions. Pulsed discharges have been used in La Plata to produce laser action at UV, visible, and infrared (IR) wavelengths corresponding to Xe III, Xe V, Xe VII, Xe VIII [30-33], Xe VI, and Xe IX [16,25]. In these investigations, time-resolved experiments were also done and relativistic Hartree-Fock calculations were also performed to obtain weighted lifetimes and radiative transition rates.

\section{Some Recent Results on Xe, Ar and Kr Ions}

The spectral analysis of several ions of xenon has a relevant impact on astronomy and laser studies. Various atomic parameters such as energy levels, oscillator strengths, transition probabilities and radiative lifetimes have many important astrophysical applications. Transition probabilities are needed for calculating the energy transport through the star in model atmospheres [34] and for direct analysis of stellar chemical compositions [35]. Xenon is a very rare element in the cosmos, observed in 
chemically peculiar stars [36] and in planetary nebulae [37]. Emission lines of $\mathrm{Kr}$ III-V, $\mathrm{Xe} \mathrm{III-V} \mathrm{in}$ a sample of planetary nebulae were identified [38] and Kr VI, Kr VII, Xe VI and Xe VII lines were recently observed in the ultraviolet spectrum of the hot DO-type white dwarf RE 0503-289 [39].

\section{1. $\mathrm{Xe} V$}

In a recent spectral analysis of four times ionized xenon, $\mathrm{Xe} \mathrm{V}, 12$ new energy levels belonging to the $5 s^{2} 5 p 6 d$ and $5 s^{2} 5 p 7 s$ configurations and 81 new classified lines were reported [40]. Using relativistic Hartree-Fock and multi-configurational Dirac-Fock calculations, the lifetimes and weighted oscillator strengths were calculated. Table 1 shows the new energy levels belonging to the configurations $5 s^{2} 5 p 6 d$ and $5 s^{2} 5 p 7 s$ and the percentage composition of these levels obtained in the least-squares fit. The calculated radiative lifetimes are also presented. The configurations involved in these transitions were $5 s^{2} 5 p 6 p, 5 s^{2} 5 p 4 f$ and $5 s 5 p^{3}, 5 s^{2} 5 p 5 d, 5 s^{2} 5 p 6 d, 5 s^{2} 5 p 6 s$, and $5 s^{2} 5 p 7 s$ for the even and odd parities. The weighted oscillator strengths for the observed lines were calculated considering fitted values for the energy parameters. The lifetime values calculated with the GRASP program are presented in the Babushkin gauge since this one, in the non-relativistic limits and in many situations, has been found to be the most stable value, in the sense that it converges smoothly as more correlation is included and is less sensitive to the details of the computational method [41].

Table 1. Experimental and calculated energy levels established for the $5 s^{2} 5 p 6 d$ and $5 s^{2} 5 p 7 s$ configurations of Xe V. Calculated radiative lifetimes are also given. Reproduced with permission from [40]. (๑ IOP Publishing. All rights reserved.)

\begin{tabular}{|c|c|c|c|c|c|}
\hline \multirow{2}{*}{\multicolumn{2}{|c|}{ Level }} & \multirow{2}{*}{ Energy Obs $\left(\mathrm{cm}^{-1}\right)$} & \multirow{2}{*}{ Percentage Composition ${ }^{a}$} & \multicolumn{2}{|c|}{ Lifetime (ns) } \\
\hline & & & & HFR & GRASP \\
\hline \multirow[t]{12}{*}{$5 s^{2} 5 p 6 d$} & ${ }^{3} \mathrm{~F}_{2}^{\circ}$ & $284871^{b}$ & $725 s^{2} 5 p 6 d^{3} F+175 s^{2} 5 p 6 d^{1} D$ & 0.48 & 0.41 \\
\hline & ${ }^{3} \mathrm{D}^{\circ}{ }_{2}$ & $287391(5)$ & $205 s^{2} 5 p 6 d^{3} P+205 s^{2} 5 p 6 d{ }^{3} D+205 s^{2} 5 p 6 d^{1} D$ & 0.29 & 0.23 \\
\hline & ${ }^{3} \mathrm{~F}_{3}^{\circ}$ & $287696(6)$ & $365 s^{2} 5 p 6 d^{3} F+175 s^{2} 5 p 6 d^{3} D+145 s^{2} 5 p 6 d^{1} F$ & 0.53 & 0.27 \\
\hline & ${ }^{3} \mathrm{D}^{\circ}{ }_{1}$ & $288830(6)$ & $515 s^{2} 5 p 6 d^{3} D+165 s^{2} 5 p 6 d^{1} P+135 s^{2} 5 p 6 d^{3} P$ & 0.28 & 0.16 \\
\hline & ${ }^{3} \mathrm{~F}_{4}^{\circ}$ & $298739(3)$ & $885 s^{2} 5 p 6 d^{3} F$ & 0.65 & 0.55 \\
\hline & ${ }^{1} \mathrm{D}^{\circ}{ }_{2}$ & $299596(3)$ & $465 s^{2} 5 p 6 d{ }^{1} D+175 s^{2} 5 p 6 d{ }^{3} D+165 s^{2} 5 p 6 d^{3} F$ & 0.34 & 0.21 \\
\hline & ${ }^{3} \mathrm{D}^{\circ}{ }_{3}$ & $300327(6)$ & $545 s^{2} 5 p 6 d^{3} D+235 s^{2} 5 p 6 d^{3} F$ & 0.28 & 0.21 \\
\hline & ${ }^{3} \mathrm{P}_{2}^{\circ}$ & $301483^{\mathrm{b}}$ & $215 s^{2} 5 p 6 d^{3} P+255 s^{2} 5 p 6 d^{3} D+145 s 5 p^{2} 6 p{ }^{5} P$ & 0.37 & 0.23 \\
\hline & ${ }^{3} \mathrm{P}^{\circ}{ }_{1}^{2}$ & $301555(5)$ & $515 s^{2} 5 p 6 d^{3} P+205 s^{2} 5 p 6 d^{3} D+155 s 5 p^{2} 6 p^{3} D$ & 0.31 & 0.21 \\
\hline & ${ }^{3} \mathrm{P}_{0}^{\circ}$ & $301998(2)$ & $905 s^{2} 5 p 6 d^{3} P$ & 0.38 & 0.25 \\
\hline & ${ }^{1} \mathrm{~F}_{3}^{\circ}$ & $304985^{b}$ & $685 s^{2} 5 p 6 d{ }^{1} F+145 s^{2} 5 p 6 d^{3} D$ & 0.24 & 0.14 \\
\hline & ${ }^{1} \mathrm{P}_{1}^{\circ}$ & $306065(7)$ & $415 s^{2} 5 p 6 d{ }^{1} P+195 s 5 p^{2} 6 p^{5} P+165 s^{2} 5 p 6 d{ }^{3} P$ & 0.35 & 0.21 \\
\hline \multirow[t]{4}{*}{$5 s^{2} 5 p 7 s$} & ${ }^{3} \mathrm{P}_{0}^{\circ}$ & $297673^{b}$ & $965 s^{2} 5 p 7 s^{3} \mathrm{P}$ & 0.16 & 0.19 \\
\hline & ${ }^{3} \mathrm{P}^{\circ}{ }_{1}$ & $298053(4)$ & $695 s^{2} 5 p 7 s^{3} P+285 s^{2} 5 p 7 s{ }^{1} P$ & 0.15 & 0.18 \\
\hline & ${ }^{3} \mathrm{P}_{2}^{\circ}$ & $312956(3)$ & $975 s^{2} 5 \mathrm{p} 7 \mathrm{~s}^{3} \mathrm{P}$ & 0.18 & 0.23 \\
\hline & ${ }^{1} \mathrm{P}^{\circ}{ }_{1}^{2}$ & $313883(4)$ & $675 s^{2} 5 p 7 s^{1} P+275 s^{2} 5 p 7 s^{3} P$ & 0.14 & 0.15 \\
\hline
\end{tabular}

Notes: ${ }^{a}$ Percentages below $5 \%$ have been omitted. ${ }^{b}$ Calculated value. ( ) Number of transitions used for establishing the levels. HFR, relativistic Hartree-Fock calculations. GRASP, general-purpose relativistic atomic structure package.

\subsection{Xe VI}

A new laser line at $33224.0 \AA$, corresponding to the five-times ionized xenon spectrum and classified as $5 s^{2} 4 f^{2} F_{7 / 2}-5 s^{2} 5 d^{2} D_{5 / 2}$ was recently observed. Semi-empirical calculations using energy parameters adjusted from least-squares were done and the obtained lifetimes were $10.55 \mathrm{~ns}$ and $0.055 \mathrm{~ns}$ for the upper and lower levels, respectively. The calculated transition probability value was $2.4 \times 10^{5} \mathrm{~s}^{-1}$. In Figure 3 the gross structure of the low configurations and the laser transition observed in Xe VI is shown. 


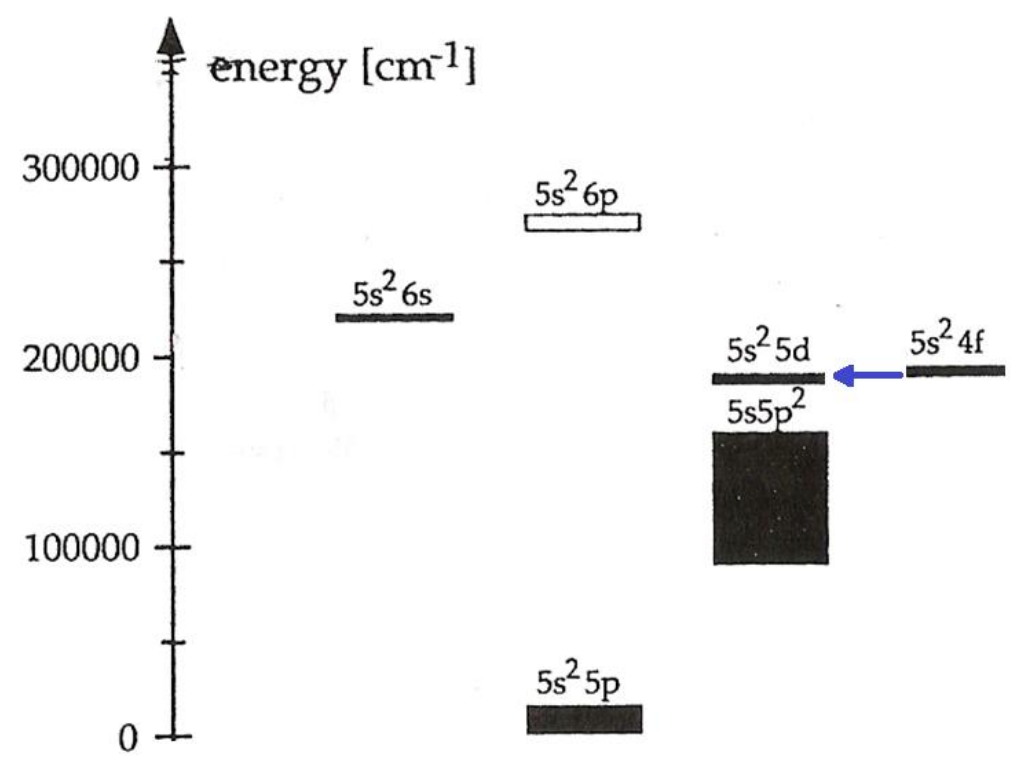

Figure 3. New $5 \mathrm{~s}^{2} 4 \mathrm{f}^{2} \mathrm{~F}_{7 / 2}-5 \mathrm{~s}^{2} 5 \mathrm{~d}^{2} \mathrm{D}_{5 / 2}$ laser line at $33224.0 \AA$ A. Reproduced by permission of IOP Publishing from [42]. (ㄷ The Royal Swedish Academy of Sciences. All rights reserved.)

The first detection of krypton and xenon in a white dwarf [39], encouraged us to extend the spectral analysis of five times ionized xenon, Xe VI. In our work the xenon spectra were recorded in the 400-5700 A region and 243 lines were observed in the experiments, 146 of which were determined for the first time. 32 new and 33 revised energy levels were reported [43]. The gf, gA and lifetimes were calculated using the HFR approach and HFR plus core polarization (HFR+CP) effects. All Xe VI lines observed in the spectrum of the hot DO-type white dwarf RE 0503-289 by Werner et al. [39] were confirmed. The Xe VI analysis is difficult because of the strong mixing of level composition and the non-smooth behavior of the structure which together result in changes in level positions and composition along the isoelectronic sequence. By using all this research, a new paper on the Xe VI ultraviolet spectrum and the xenon abundance in the hot DO-type white dwarf RE 0503-289 was also reported [44].

\subsection{Xe VII and Xe VIII}

Considering that the red laser line at $6699.40 \AA$ remains unclassified and taking into account the detection of Xe VII in a white dwarf [39], we have decided to make a new spectral analysis of the six- and seven-times ionized xenon spectra. Thus, by using our experimental data covering the wavelength range $430-4640 \AA, 40$ new transitions of Xe VII and 25 of Xe VIII were classified. We have also revised the values for the previously known energy levels and extended the analysis for Xe VII to 10 new energy levels belonging to $5 s 6 d, 5 s 7 s$ and $5 s 7 p, 4 d^{9} 5 s^{2} 5 p$ even and odd configurations, respectively. Seven new energy levels of the $4 d^{9} 5 s 5 d$ core excited configuration of Xe VIII were determined [45]. Relativistic Hartree-Fock and least-squares-fitted parametric calculations were used in the interpretation of the observed spectra.

\section{4. $A r V I$}

The analysis of the atomic spectra of five times ionized argon (Ar VI), that belongs to the $\mathrm{Al}$ I isoelectronic sequence, can be used for studies related with electron-correlation calculations of excited-state structures. As another example of noble gas studies that also have astrophysical interest, an extended analysis of the $3 s^{2} 4 p, 3 s^{2} 5 d, 3 s^{2} 5 s, 3 s 3 d^{2}, 3 s 3 p 3 d, 3 s 3 p 4 p$, and $3 p^{2} 3 d$ configurations in $\mathrm{Ar} \mathrm{VI}$, including the determination of new classified lines and energy levels belonging to these configurations, using $\mathrm{Al}$ I isoelectronic data and HFR calculations, was completed. Atomic transitions 
are expected to be prominent in the absorption spectra of interstellar gas clouds [46], and Ar ions have been identified in the Markarian 3 galaxy [47] Chandra HETGS spectrum. In our analysis 14 new energy levels for the configurations $3 \mathrm{~s} 3 \mathrm{p} 3 \mathrm{~d}, 3 \mathrm{~s}^{2} 4 \mathrm{p}, 3 \mathrm{~s}^{2} 5 \mathrm{~s}, 3 \mathrm{p}^{2} 3 \mathrm{~d}, 3 \mathrm{~s} 3 \mathrm{~d}^{2}$ were established, and two adjusted energy levels of the configuration $3 s^{2} 5 \mathrm{~d}$ and 68 new spectral lines were classified [48]. Rydberg series interactions for the $3 \mathrm{~s} 3 \mathrm{p} 3 \mathrm{~d}$ configuration were included as their configuration interaction integrals have shown significant values.

Figure 4 shows the gross structure of the Ar VI configurations and in Figure 5 the behavior of the $\lambda_{\text {obs }}-\lambda_{\text {cal }}$ versus the net charge for the $3 \mathrm{~s} 3 \mathrm{p}\left({ }^{1} \mathrm{P}\right) 3 \mathrm{~d}^{2} \mathrm{~F}_{5 / 2}-3 \mathrm{~s} 3 \mathrm{~d}^{2}{ }^{2} \mathrm{G}_{7 / 2}$ transition in the Al I sequence is shown.

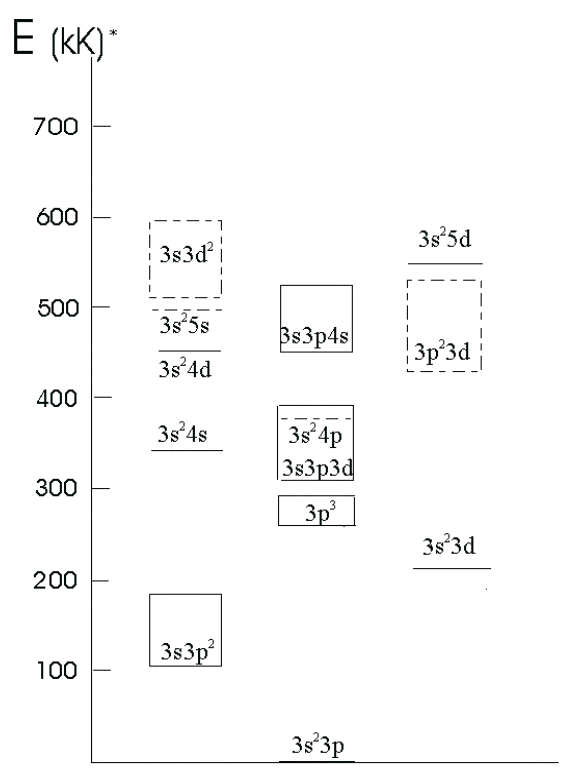

Figure 4. Gross structure of the experimental and theoretical (dotted line) Ar VI configurations. ' $\mathrm{kK}$ ' means $10^{3} \mathrm{~cm}^{-1}$. Reproduced by permission of IOP Publishing from [48]. (๑ The Royal Swedish Academy of Sciences. All rights reserved.)

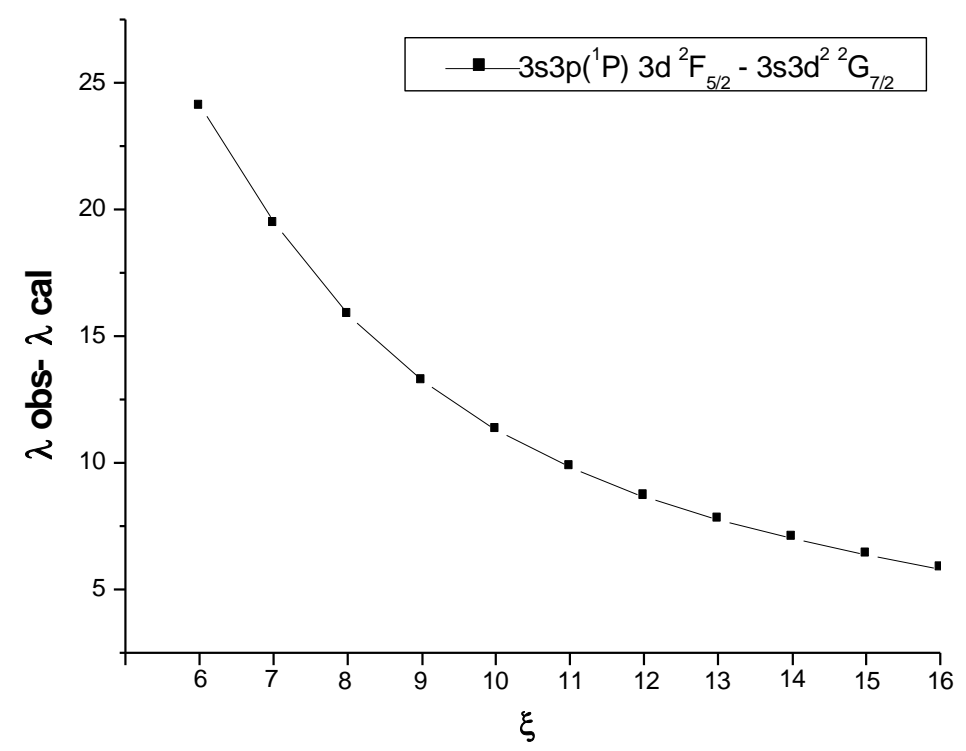

Figure 5. $\lambda_{\text {obs }}-\lambda_{\text {cal }}$ versus the net charge for the $3 s 3 p\left({ }^{1} \mathrm{P}\right) 3 \mathrm{~d}{ }^{2} \mathrm{~F}_{5 / 2}-3 \mathrm{~s} 3 \mathrm{~d}^{2}{ }^{2} \mathrm{G}_{7 / 2}$ transition in the Al I sequence. Reproduced by permission of IOP Publishing from [48]. (๑ The Royal Swedish Academy of Sciences. All rights reserved.) 


\section{5. $\mathrm{Kr} V$}

Forbidden lines belonging to $\mathrm{Kr}$ V transitions were found in many nebulae, such as NGC 2440 [49], IC2501 [49], IC4191 [49], and Hen2-436 [50]. The forbidden Kr V lines have not been directly observed at the laboratory, and their wavelengths are presumed from energy differences between the ground configuration levels. Therefore, a precise determination of such levels is crucial for the establishment of the wavelengths of these lines.

Using experimental data from a $\theta$-pinch and a pulsed discharge, an extended analysis of the $\mathrm{Kr} \mathrm{V}$ spectrum was conducted. The spectrum was recorded in the 230-4900 A wavelength range, resulting in 91 new classified lines. We were able to identify 21 new energy levels belonging to the $4 s^{2} 4 p 5 d$, $4 s^{2} 4 p 5 s, 4 s^{2} 4 p 6 s, 4 s^{2} 4 p 5 p$, and $4 s 4 p^{2} 4 d$ configurations [51]. Relativistic Hartree-Fock calculations were used to predict energy levels and transitions and, at this stage, it is important to mention the strong interaction that exists between the ground configuration with the $4 \mathrm{p}^{4}$ and the $4 \mathrm{~s} 4 \mathrm{p}^{2} 4 \mathrm{~d}$ configurations in this ion. This behavior was also observed with the $\mathrm{s}^{2} \mathrm{p}^{2}, \mathrm{p}^{4}$, and $\mathrm{sp}^{2} \mathrm{~d}$ configurations in the spectral analysis of $\mathrm{Xe} \mathrm{V}$ and $\mathrm{Ar} \mathrm{V}$ [31,52].

After this research, a new study on lifetimes and transition probabilities in four times ionized krypton was completed. The gf, gA and lifetimes were calculated for all experimentally known dipole transitions and levels of $\mathrm{Kr} \mathrm{V}$. The values were determined by four methods. Three of them were based on the Hartree-Fock method including relativistic corrections (the first including a small set of configurations, the second a large set, and the third including core-polarization effects) with electrostatic parameters optimized by a least-squares procedure, in order to obtain energy levels adjusted to the corresponding experimental values. The fourth method was based on a relativistic multiconfigurational Dirac-Fock approach. The 313 dipole electric lines reported in the 294-3615 region, included 47 new classified lines [53]. In this investigation, we have also related the observed line intensity with $\log _{10}$ (gA) by the statistical correlation coefficient. The analysis was disaggregated by transition arrays between configurations, i.e., between levels with the same set of dominant configurations in their eigenvector composition. Thirteen sets of transitions were identified, and results are shown in Table 2. Comparing the correlation factors, the best results are for HFR large set of configurations, with or without $\mathrm{CP}$, with an average value of 0.40 . These calculations display the best values for more than half of the arrays analyzed. The inclusion of CP effects does not cause significant differences in results.

Table 2. Statistical correlation between $\log _{10} \mathrm{gA}$ and experimental line intensity. Maximum correlation for each transition array in boldface. Reproduced with permission from [53]. (๔ IOP Publishing. All rights reserved.)

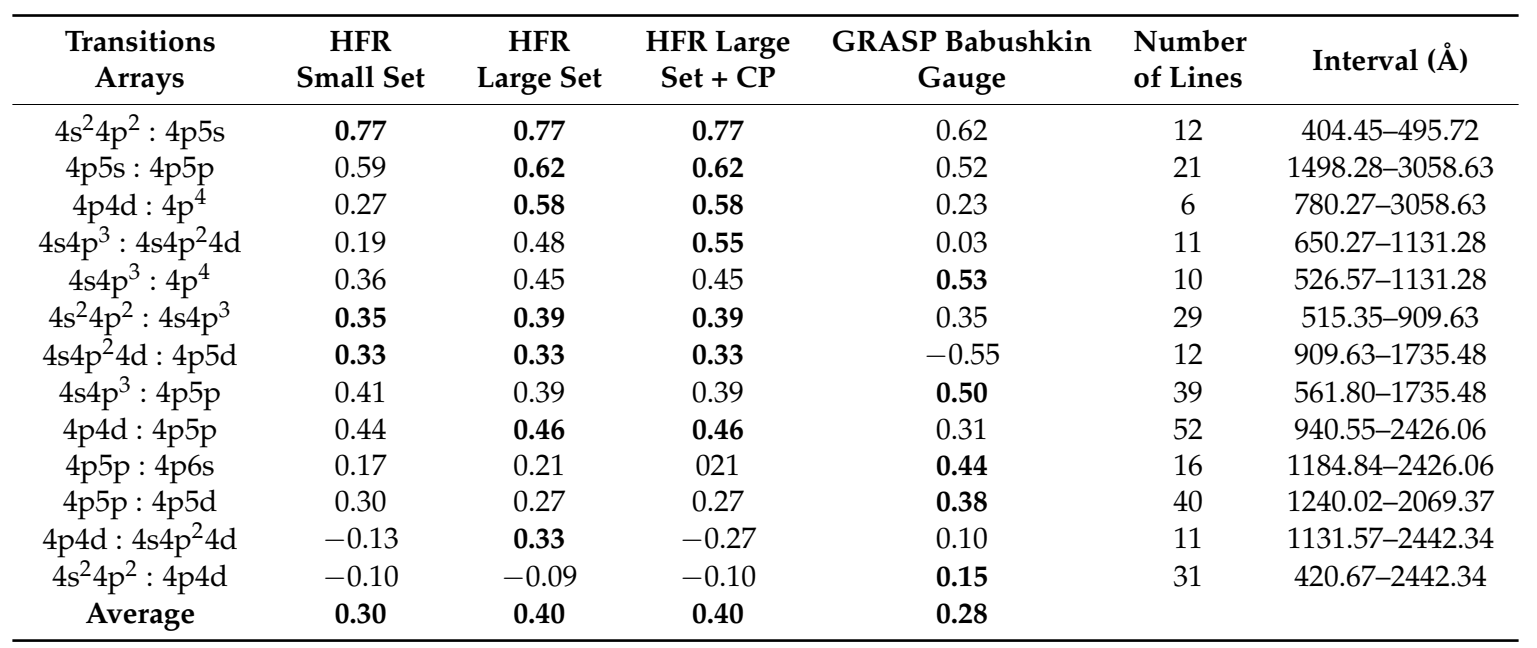




\section{6. $K r V I$}

In the first work carried out on this ion the spectrum of five-time ionized krypton was recorded in the 240-2600 $\AA$ using both light sources previously described. The study involved the $4 \mathrm{~s} 4 \mathrm{p} 4 \mathrm{~d}$ and the 4s4p5s configurations resulting in 109 new line classifications and 22 new energy levels [54]. This analysis also showed the strong interaction between the $4 \mathrm{~s} 4 \mathrm{p} 4 \mathrm{~d}$ configurations and the other $n=4$ complex configurations. Oscillator strengths calculated from fitted values of the energy parameters that give gf values that are in better agreement with line intensity observations, were also reported [55].

In a recent analysis [56], 61 lines as transitions between levels of configurations $4 \mathrm{p}^{3}, 4 \mathrm{~s}^{2} 5 \mathrm{p}$, $4 \mathrm{~s} 4 \mathrm{p} 4 \mathrm{~d}, 4 \mathrm{~s} 4 \mathrm{p} 5 \mathrm{~s}$, and 4s4p5p were classified for the first time and all the 18 energy levels belonging to $4 \mathrm{~s} 4 \mathrm{p} 5 \mathrm{p}$ configuration except one were determined. Eight new energy level values corresponding to configurations $4 \mathrm{~s} 4 \mathrm{p} 4 \mathrm{f}$ and $4 \mathrm{p}^{2} 4 \mathrm{~d}$, supported by 26 new classified lines, were also determined and used in the interpretation of the observed $4 s 4 p 5 p$ configuration. In Figure 6 , the gross structure of the observed Kr VI configurations is shown. The dashed arrows indicate the $4 \mathrm{~s} 4 \mathrm{p} 5 \mathrm{p}-4 \mathrm{p}^{3}, 4 \mathrm{~s} 4 \mathrm{p} 5 \mathrm{p}-4 \mathrm{~s}^{2} 5 \mathrm{p}$, $4 \mathrm{~s} 4 \mathrm{p} 5 \mathrm{p}-4 \mathrm{~s} 4 \mathrm{p} 4 \mathrm{~d}$, and 4s4p5p-4s4p5s transitions identified in this work.

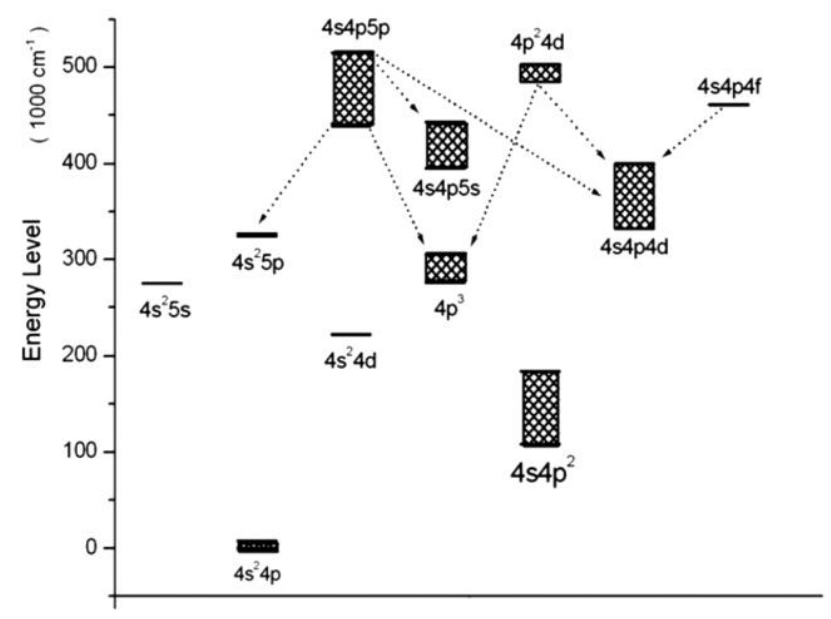

Figure 6. Gross structure of the observed Kr VI configurations. Reproduced by permission of IOP Publishing from [56]. (@ The Royal Swedish Academy of Sciences. All rights reserved.)

\section{7. $\mathrm{Kr} V I I$}

Six times ionized krypton belongs to the $\mathrm{Zn}$ I isoelectronic sequence and has the ground configuration $3 \mathrm{~d}^{10} 4 \mathrm{~s}^{2}$. Due to the considerable interest in the diagnosis of high-temperature laboratory and astrophysical plasmas, the spectra of this sequence has been extensively studied and the first detection of Kr VII in a white dwarf was recently reported [39]. The spectra of the Zn-like Kr ion has been studied by the use of different light sources and by using a $\theta$-pinch and a pulsed electrical discharge tube [16] in the region from 300 to $4800 \AA$. The values for the previously known energy levels were revised and a new extended analysis resulting in 115 new classified lines and 38 new energy levels belonging to 4s5s, 4s6s, 4p4f, 4s6d and 4p4d, 4s5p, 4s4f, 4p5s, 4s5f, 4s6p, 4s6f even and odd configurations were completed [57]. For the prediction of the energy level values we studied the behavior of the difference between the observed and calculated energy values along the isoelectronic sequence. As an example, Figure 7 shows the interpolated value for the $4 \mathrm{p} 5 \mathrm{~s}{ }^{3} \mathrm{P}_{1} \mathrm{E}_{\mathrm{obs}}-\mathrm{E}_{\mathrm{cal}}$ of $\mathrm{Kr}$ VII in the $\mathrm{Zn}$-like sequence. The adjusted energy difference value represented in A using our new energy level value in $587029 \mathrm{~cm}^{-1}$ fits better than the value in $587068 \mathrm{~cm}^{-1}$ reported in Ref. [58], as shown in B. 


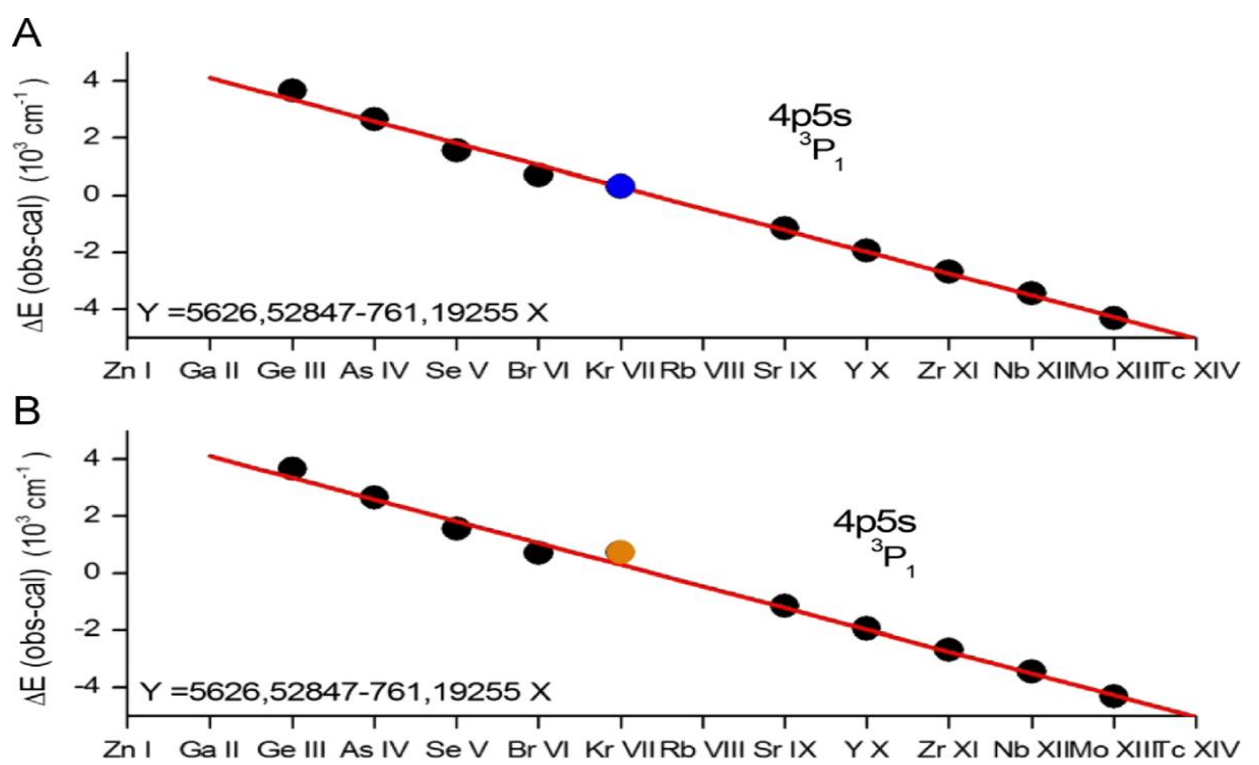

Figure 7. Interpolated value for the $4 \mathrm{p} 5 \mathrm{~s}{ }^{3} \mathrm{P}_{1} \mathrm{E}_{\mathrm{obs}}-\mathrm{E}_{\mathrm{cal}}$ of $\mathrm{Kr}$ VII in the Zn-like sequence. Our new adjusted energy difference value represented in (A) fits better than the value reported in Ref. [58]; as shown in (B). Reproduced by permission of IOP Publishing from [57]. (C The Royal Swedish Academy of Sciences. All rights reserved.)

We have recently reported the study of the $4 \mathrm{p}^{2}, 5 \mathrm{p}^{2}$, and $5 \mathrm{~s} 5 \mathrm{f}$ excited configurations of the Zn I and $\mathrm{Cd} I$ isoelectronic sequences, using relativistic and non-relativistic semi-empirical approaches [59]. The configuration $5 \mathrm{~s} 5 \mathrm{f}$ was also analyzed taking into account the Landés interval rule. In this research, different semi-empirical approaches considering the linearity of the Slater integrals for large $\mathrm{Z}$, the smoothness of the sF screening parameters, the energy values in terms of $\mathrm{Z}$, and the differences of the $E_{o b s}-E_{c a l}$ values were used. $E_{c a l}$ values means the energies calculated with HFR, and $E_{o b s}$ are the experimental values.

It is important to mention that most of our results on the studied xenon, krypton, and argon gases were critically compiled and reported by E.B. Saloman [60-62] and an extension and new level optimization of the Ne IV spectrum, that includes our line identification on this gas, was recently made by A. Kramida [63]. Also our previous results a new Kr IV-VII oscillator strengths and an improved spectral analysis of the hot, hydrogen-deficient DO-type white dwarf RE 0503-289, and a new $\mathrm{Zr}$ IV-VII, Xe IV-V, and Xe VII oscillator strengths and the Al, Zr, and Xe abundances in the hot white dwarfs G191-B2B and RE 0503-289 were very recently reported [64,65].

\section{Conclusions}

A comprehensive review concerning the spectral analysis of several moderately charged rare-gas atoms carried out by our international collaborative groups was presented. New and earlier analyses for these ions were revised and extended. Semi-empirical approaches with relativistic Hartree-Fock and Dirac-Fock calculations were used in the studies. The spectra were recorded from the VUV to the near-IR regions using two different light sources, a pulsed electrical discharge tube, and a $\theta$-pinch discharge.

It is important to point out that both spectral sources, together with the detection and measuring systems previously described, allowed us to generate a large amount of new spectral data with very good accuracy in a wide spectral range. Some experimental data used for the study of moderately charged rare-gas atoms, obtained with other kinds of spectral sources such as beam-foil or collision-based spectroscopy, were improved. 
Most of our experimental data were obtained using the pulsed electrical discharge tube source. An important characteristic of this light source is that it generates very rich ion spectra, requiring much less capacity and current in the electric discharge, and producing ion spectra like those generated in the $\theta$-pinch.

The pulsed electrical discharge tube also showed that it is a very suitable spectral source for the studies related with the population mechanisms involved in the laser emission of different xenon ions. It is important to continue these works using both time-resolved and frequency spectroscopy under different experimental conditions, together with lifetimes and transition probability calculations for the involved energy levels and lines responsible for the laser emission. Specifically, it is important to extend the theoretical and experimental studies in eight times ionized xenon, where stimulated emission in the VUV was observed on the $4 \mathrm{~d}^{9} 5 \mathrm{p}^{1} \mathrm{P}_{1}-4 \mathrm{~d}^{9} 5 \mathrm{~d}^{1} \mathrm{~S}_{0}$ transition in the Pd-like Xe ion. It is necessary to analyze how the $4 \mathrm{~d}^{9} 4 \mathrm{f}$ configuration affects the plasma dynamics in the Pd-like ions, where the $4 \mathrm{~d}^{9} 4 \mathrm{f}^{1} \mathrm{P}_{1}-4 \mathrm{~d}^{9} 5 \mathrm{~d}^{1} \mathrm{~S}_{0}$ transition has conditions for laser action in high ions on this sequence. Similar studies on this subject in the Ne-like and Ni-like ions are also important to conduct.

The experimental device that we used to obtain noble gas spectra can also be applied for the study of non noble gases. In fact, the pulsed electrical discharge tube was used in the works on the $\mathrm{N}_{2}$ laser, showing very high accuracy in the obtained results [3-5]. The $\theta$-pinch discharge was also used for oxygen ion studies [66] (and references therein).

Interpreting the atomic observations theoretically and by testing computational predictions by experimental data are interactive processes. In the comparison, the high resolution spectral data show better computational results. This was used in all our works.

Discrepancies between experimental measurements and the theoretical calculations led us to carry out more accurate predictions of the allowed and forbidden transitions. MCDF calculations including more active orbitals enabled dealing with a larger amount of excited configurations. The differences of the gauge values in length and velocity of the E1 oscillator strengths obtained showed the accuracy of our calculations GRASP in the performed studies on $\mathrm{Kr} \mathrm{V}$, Xe V, and Xe IX.

In HFR calculations for $\mathrm{Kr} \mathrm{V}, \mathrm{Xe} \mathrm{V}, \mathrm{Xe} \mathrm{VI}$, and Xe IX, CP effects were included, which, combined with a semi-empirical optimization of radial parameters, minimized the discrepancies between the calculated levels of energy and those experimentally obtained. In this type of calculation, the cancellation factors [20] were also assessed, indicating when the oscillator intensities and transition probabilities were affected by great uncertainty.

The spectral analysis of ionized noble gases related with astrophysics and laser studies will be continued in our future work by using the obtained experimental material, different computational calculations, and semi-empirical approximations.

During all these years of fruitful work, fluid collaborations involved groups working on similar subjects in Argentina (Centro de Investigaciones Opticas, Universidad Nacional del Centro, and Universidad Nacional de Mar del Plata); in Brazil (University of Campinas, Universidad Federal Fluminense, and Universidad Federal de Roraima); in Colombia (Universidad del Atlántico); and in Sweden (University of Lund). These collaborations generated mutual visits performed by scientists and students for courses and/or joint work, the exchange of scientific material, the production of more than a dozen of $\mathrm{PhD}$ theses, more than seventy international papers, three book chapters, and various reports to international conferences.

Acknowledgments: The careful reading and comments of the manuscript by M. Garavaglia, and Dra. M. Tebaldi are gratefully acknowledged. The Comisión de Investigaciones Científicas de la Provincia de Buenos Aires (CICPBA), Argentina-where J.G. Reyna Almandos and M. Raineri are researchers—is also gratefully acknowledged.

Author Contributions: J.R.A. conceived and wrote the paper. M.R. had important participation in the discussions on the final version.

Conflicts of Interest: The authors declare no conflict of interest. 


\section{References}

1. Giacchetti, A.; Gallardo, M.; Garavaglia, M.; González, Z.; Valero, F.P.J.; Zakowicz, E. Interferometrically measured thorium wavelengths. J. Opt. Soc. Am. 1964, 54, 957-959. [CrossRef]

2. Andrade, O.; Gallardo, M.; Bockasten, K. High-gain laser lines in noble gases. Appl. Phys. Lett. 1967, 11, 99-100. [CrossRef]

3. Andrade, O.; Gallardo, M.; Bockasten, K. New lines in a pulsed $\mathrm{N}_{2}$ laser. Appl. Opt. 1967, 6, 2006. [CrossRef] [PubMed]

4. Gallardo, M.; Massone, C.A.; Garavaglia, M. Superradiant and laser spectroscopy in the second positive system of $\mathrm{N}_{2}$. Appl. Opt. 1968, 7, 2418. [CrossRef] [PubMed]

5. Garavaglia, M.; Gallardo, M.; Massone, C.A. On the interaction between the first and the second positive laser system in $\mathrm{N}_{2}$. Phys. Lett. 1969, 28A, 787-788. [CrossRef]

6. Gallardo, M.; Garavaglia, M.; Tagliaferri, A.A.; Gallego Lluesma, E. About unidentified ionized Xe laser lines. IEEE J. Quantum Electron. 1970, 6, 745-747. [CrossRef]

7. Gallego Lluesma, E.; Tagliaferri, A.A.; Massone, C.A.; Garavaglia, M.; Gallardo, M. Ionic assignment of unidentified xenon laser lines. J. Opt. Soc. Am. 1973, 63, 362-364. [CrossRef]

8. Gallardo, M.; Massone, C.A.; Tagliaferri, A.A.; Garavaglia, M.; Persson, W. $5 s^{2} 5 p^{3}\left({ }^{4} S\right)$ nl levels of Xe III. Phys. Scr. 1979, 19, 538-544. [CrossRef]

9. Hansen, J.E.; Meijer, F.G.; Outred, M.; Persson, W.; Di Rocco, H.O. Identification of the $4 \mathrm{~d}^{10} 5 \mathrm{p}^{61} \mathrm{~S}_{0}$ level in Xe III using optical spectroscopy. Phys. Scr. 1983, 27, 254-255. [CrossRef]

10. Trigueiros, A.; Pettersson, S.-G.; Reyna Almandos, J.G. Transitions within the $\mathrm{n}=4$ complex of Kr VII obtained from a $\theta$-pinch light source. Phys. Scr. 1986, 34, 164-166. [CrossRef]

11. Bredice, F.; Reyna Almandos, J.G.; Gallardo, M.; DiRocco, H.O.; Trigueiros, A.G. Revised and extended analysis of the low configurations in Kr III. J. Opt. Soc. Am. B 1988, 5, 222-235. [CrossRef]

12. Trigueiros, A.G.; Pagan, C.J.B.; Reyna Almandos, J.G. Energy levels of the configurations $4 s^{2} 4 \mathrm{p}, 4 \mathrm{~s}^{2} \mathrm{p}^{2}, 4 \mathrm{~s}^{2} 4 \mathrm{~d}$, and $4 \mathrm{~s}^{2} 5 \mathrm{p}$ in Kr VI, obtained from a $\theta$-pinch light source. Phys. Rev. A 1988, 38, 166-169. [CrossRef]

13. Persson, W.; Wahlström, C.G.; Bertuccelli, G.; Di Rocco, H.O.; Reyna Almandos, J.G.; Gallardo, M. Spectrum of doubly ionized xenon (Xe III). Phys. Scr. 1988, 38, 347-369. [CrossRef]

14. Reyna Almandos, J.G.; Bredice, F.; Gallardo, M.; Pagan, C.J.B.; Di Rocco, H.O.; Trigueiros, A.G. $5 s^{2} 5 p^{2}(5 d+6 s)$ configurations in triply ionized xenon (Xe IV). Phys. Rev. A 1991, 43, 6098-6103. [CrossRef] [PubMed]

15. Raineri, M.; Bredice, F.; Gallardo, M.; Reyna Almandos, J.G.; Pagan, C.J.B.; Trigueiros, A.G. Revised and extended analysis of five times ionized argon (Ar VI). Phys. Scr. 1992, 45, 584-589. [CrossRef]

16. Reyna Almandos, J.; Bredice, F.; Raineri, M.; Gallardo, M. Spectral analysis of ionized noble gases and implications for astronomy and laser studies. Phys. Scr. T 2009, 134, 014018. [CrossRef]

17. Trigueiros, A.G.; Machida, M.; Pagan, C.J.B.; Reyna Almandos, J.G. The spectroscopic study of radiation produced in a $\theta$-pinch. Nucl. Instrum. Methods Phys. Res. A 1989, 280, 589-592. [CrossRef]

18. Pettersson, S.-G. The spectrum of O III. Phys. Scr. 1982, 26, 296-318. [CrossRef]

19. Valero, F.P.J. Improved Values for energy Levels, Ritz Standards, Interferometrically Measured Wavelengths in Th I. J. Opt. Soc. Am. 1968, 58, 1048-1053. [CrossRef]

20. Cowan, R.D. The Theory of Atomic Structure and Spectra; Cambridge University Press: Cambridge, MA, USA, 1981; pp. 178-202.

21. Curtis, L.J. Atomic Structure and Lifetimes: A Conceptual Approach; Cambridge University Press: Cambridge, MA, USA, 2003; pp. 54-58.

22. Biémont, E.; Quinet, P.; Zeippen, C.J. Transition Probabilities in Xe V. Phys. Scr. 2005, 71, 163-169. [CrossRef]

23. Biémont, E.; Buchard, V.; Garnir, H.-P.; Lefebvre, P.-H.; Quinet, P. Radiative lifetime and oscillator strength determinations in Xe VI. Eur. Phys. J. D 2005, 33, 181-191.

24. Biemont, E.; Clar, M.; Fivet, V.; Garnir, H.-P.; Palmeri, P.; Quinet, P.; Rostohar, D. Lifetime and transition probability determination in xenon ions. The cases of Xe VII and Xe VIII. Eur. Phys. J. D 2007, 44, $23-33$. [CrossRef]

25. Gallardo, M.; Raineri, M.; Reyna Almandos, J.; Biémont, É. New energy levels, calculated lifetimes and transition probabilities in Xe IX. J. Phys. B 2011, 44, 045001. [CrossRef]

26. Dyall, K.G.; Grant, I.P.; Johnson, C.T.; Parpia, F.A.; Plummer, E.P. GRASP: A general-purpose relativistic atomic structure program. Comput. Phys. Commun. 1989, 55, 425-456. [CrossRef] 
27. Humphreys, C.J. The Third Spectrum of Krypton. Phys. Rev. 1935, 47, 712-717. [CrossRef]

28. Di Rocco, H.O.; Bertuccelli, G.; Reyna Almandos, J.G.; Gallardo, M. Line shift of singly ionized xenon in high current pinched discharges. J. Quant. Spectrosc. Radiat. Transf. 1986, 35, 443-446. [CrossRef]

29. Di Rocco, H.O.; Bertuccelli, G.; Reyna Almandos, J.; Bredice, F.; Gallardo, M. Line shift of Kr II, Kr III, and Xe III in high-current, pinched discharges. J. Quant. Spectrosc. Radiat. Transf. 1989, 41, 161-165. [CrossRef]

30. Duchowicz, R.; Schinca, D.; Gallardo, M. New analysis for the assignment of UV-visible ionic Xe laser lines. IEEE J. Quant. Elect. 1994, 30, 155-159. [CrossRef]

31. Gallardo, M.; Raineri, M.; Reyna Almandos, J.G.; Sobral, H.; Callegari, F. Revised and extended analysis in four times ionized xenon, Xe V. J. Quant. Spectrosc. Radiat. Transf. 1999, 61, 319-327. [CrossRef]

32. Sobral, H.; Schinca, D.; Gallardo, M.; Duchowicz, R. Time dependent study of a Multi-Ionic Xenon plasma. J. Appl. Phys. 1999, 85, 69-73. [CrossRef]

33. Sobral, H.; Raineri, M.; Schinca, D.; Gallardo, M.; Duchowicz, R. Excitation Mechanisms and Characterization of a Multi-Ionic Xenon Laser. IEEE J. Quantum Electron. 1999, 35, 1308-1313. [CrossRef]

34. Gustafsson, B. The Future of Stellar Spectroscopy and its Dependence on YOU. Phys. Scr. 1991, 34, 14-19. [CrossRef]

35. Biémont, E.; Blagoev, K.; Campos, J.; Mayo, R.; Malcheva, G.; Ortíz, M.; Quinet, P. Radiative parameters for some transitions in $\mathrm{Cu}(\mathrm{II})$ and $\mathrm{Ag}(\mathrm{II})$ spectrum. J. Electron. Spectrosc. Relat. Phenom. 2005, 27, 144-147. [CrossRef]

36. Cowley, C.R.; Hubrig, S.; Palmeri, P.; Quinet, P.; Biémont, É.; Wahlgren, G.M.; Schütz, O.; González, H.D. 65949: Rosetta stone or red herring. Mon. Not. R. Astron. Soc. 2010, 405, 1271-1284. [CrossRef]

37. Otsuka, M.; Tajitsu, A. Chemical abundances in the extremely carbon-rich and xenon-rich halo planetary nebula H4-1. Astrophys. J. 2013, 778, 146-158. [CrossRef]

38. Zhang, Y.; Liu, X.-W. Fe/Ni ratio in the Ant Nebula Mz3. Proc. IAU Symp. 2006, 2, 547-548. [CrossRef]

39. Werner, K.; Rauch, T.; Ringat, E.; Kruk, J.W. First detection of krypton and xenon in a White dwarf. Astrophys. J. 2012, 753, L7. [CrossRef]

40. Raineri, M.; Gallardo, M.; Padilla, S.; Reyna Almandos, J. New energy levels, lifetimes and transition probabilities in four times ionized xenon (Xe V). J. Phys. B 2009, 42, 205004. [CrossRef]

41. Froese Fischer, C.; Rubin, R.H. Transition rates for some forbidden lines in Fe IV. J. Phys. B 1998, 31, 1657-1669. [CrossRef]

42. Larsson, M.O.; Gonzalez, A.M.; Hallin, R.; Heijkenskjöld, F.; Nyström, B.; O’Sullivan, G.; Weber, C.; Wännström, A. Wavelengths and Energy Levels of Xe V and Xe VI Obtained by Collision-based Spectroscopy. Phys. Scr. 1996, 53, 317-324. [CrossRef]

43. Gallardo, M.; Raineri, M.; Reyna Almandos, J.; Pagan, C.J.B.; Abrahao, R.A. Revised and extended analysis of five times ionized xenon, Xe VI. Astophys. J. Suppl. 2015, 216, 11. [CrossRef]

44. Rauch, T.; Hoyer, D.; Quinet, P.; Gallardo, M.; Raineri, M. The Xe VI ultraviolet spectrum and the xenon abundance in the hot DO-type white dwarf RE 0503-289. Astron. Astrophys. 2015, 577, A88. [CrossRef]

45. Raineri, M.; Gallardo, M.; Reyna Almandos, J.; Pagan, C.J.B.; Sarmiento, R. Extended analysis of Xe VII and Xe VIII. Can. J. Phys. 2017, in press. [CrossRef]

46. Morton, D.C.; Smith, W.H. A Summary of Transition Probabilities for Atomic Absorption Lines Formed in Low-Density Clouds. Astrophys. Suppl. Scr. 1973, 26, 333-363. [CrossRef]

47. Sako, M.; Kahn, S.M.; Paerels, F.; Liedahl, D.A. The Chandra High-Energy Transmission Grating Observation of an X-Ray Ionization Cone in Markarian 3. Astrophys. J. 2000, 543, L115-L118. [CrossRef]

48. Raineri, M.; Gallardo, M.; Borges, F.O.; Trigueiros, A.G.; Reyna Almandos, J. Extended analysis of the Al-like argon spectrum. Phys. Scr. 2009, 79, 025302. [CrossRef]

49. Sharpee, B.; Zhang, Y.; Williams, R.; Pellegrini, E.; Cavagnolo, K.; Baldwin, J.A.; Phillips, M.; Liu, X.W. Photoionization cross sections for the trans-iron element $\mathrm{Se}^{+}$from 18 to $31 \mathrm{eV}$. Astrophys. J. 2007, 659, 1265-1290. [CrossRef]

50. Otsuka, M.; Meixner, M.; Riebel, D.; Hyung, S.; Tajitsu, A.; Izumiura, H. Dust and chemical abundances of the Sagittarius dwarf galaxy planetary nebula Hen 2-436. Astrophys. J. 2011, 729, 39. [CrossRef]

51. Rezende, D.C.J.; Borges, F.O.; Cavalcanti, G.H.; Raineri, M.; Gallardo, M.; Reyna Almandos, J.; Trigueiros, A.G. Extended analysis of the Kr V spectrum. J. Quant. Spectrosc. Radiat. Transf. 2010, 111, 2000-2006. [CrossRef]

52. Cavalcanti, G.; Trigueiros, A.; Gallardo, M.; Reyna Almandos, J. Study of the $3 \mathrm{p}^{4}$ configuration in four times ionized argon, Ar V. J. Phys. B 1996, 29, 6049-6053. [CrossRef] 
53. Raineri, M.; Gallardo, M.; Pagan, C.J.B.; Trigueiros, A.G.; Reyna Almandos, J. Lifetimes and transition probabilities in Kr V. J. Quant. Spectrosc. Radiat. Transf. 2012, 113, 1612-1627. [CrossRef]

54. Pagan, C.J.B.; Reyna Almandos, J.; Gallardo, M.; Pettersson, S.-G.; Cavalcanti, G.; Trigueiros, A.G. Study of the 4s4p4d and 4s4p5s configurations of Kr VI. J. Opt. Soc. Am. B 1995, 12, 203-211. [CrossRef]

55. Pagan, C.J.B.; Raineri, M.; Bredice, F.; Reyna Almandos, J.; Gallardo, M.; Pettersson, S.-G.; Cavalcanti, G.; Trigueiros, A.G. Weighted oscillator strengths for Kr VI spectrum. J. Quant. Spectrosc. Radiat. Transf. 1996, 55, 163-168. [CrossRef]

56. Farias, E.E.; Raineri, M.; Gallardo, M.; Reyna Almandos, J.; Cavalcanti, G.H.; Borges, F.O.; Trigueiros, A.G. New energy levels and transitions for the 4s4p5p configuration in Kr VI. J. Quant. Spectrosc. Radiat. Transf. 2011, 112, 2463-2468. [CrossRef]

57. Raineri, M.; Farías, E.E.; Souza, J.O.; Amorim, E.; Gallardo, M.; Reyna Almandos, J. Revised and extended analysis of the Zn-like Kr íon. J. Quant. Spectrosc. Radiat. Transf. 2014, 148, 90-98. [CrossRef]

58. Churilov, S.S. Analysis of the spectrum of the Zn-like Kr VII Ion: Highly excited 4p4d and 4p5s configurations. Opt. Spectrosc. 2002, 93, 826-832. [CrossRef]

59. Di Rocco, H.O.; Raineri, M.; Reyna Almandos, J. Study of the $4 \mathrm{p}^{2}, 5 \mathrm{p}^{2}$ and $5 \mathrm{~s} 5 \mathrm{f}$ excited configurations of the $\mathrm{Zn}$ and $\mathrm{Cd}$ isoelectronic sequences, using relativistic and non-relativistic semi empirical approaches. Eur. Phys. J. D 2016, 70, 239. [CrossRef]

60. Saloman, E.B. Energy levels and Observed spectral lines of xenon, Xe I through Xe LIV. J. Phys. Chem. Ref. Data 2004, 33, 765-921. [CrossRef]

61. Saloman, E.B. Energy levels and Observed spectral lines of krypton, Kr I through Kr XXXVI. J. Phys. Chem. Ref. Data 2007, 36, 215-386. [CrossRef]

62. Saloman, E.B. Energy levels and Observed spectral lines of argon, Ar II through Ar XVIII. J. Phys. Chem. Ref. Data 2010. [CrossRef]

63. Kramida, A.; Brown, C.M.; Feldman, U.; Reader, J. Extension and new level optimization of The Ne IV spectrum. Phys. Scr. 2012, 85, 025303. [CrossRef]

64. Rauch, T.; Quinet, P.; Hoyer, D.; Werner, K.; Richter, P.; Kruk, J.W.; Demleitner, M. New Kr IV-VII oscillator strengths and an improved spectral analysis of the hot, hydrogen-deficient DO-type white dwarf RE 0503-289. Astron. Astrophys. 2016. [CrossRef]

65. Rauch, T.; Gamrath, S.; Quinet, P.; Löbling, L.; Hoyer, D.; Werner, K.; Kruk, J.W.; Demleitner, M. New Zr IV-VII, Xe IV-V, and Xe VII oscillator strengths and the $\mathrm{Al}, \mathrm{Zr}$, and $\mathrm{Xe}$ abundances in the hot white dwarfs G191-B2B and RE 0503-289. Astron. Astrophys. 2016. [CrossRef]

66. Reyna Almandos, J.; Hutton, R. Light Sources for Atomic Spectroscopy. Handbook for Highly Charged Ion Spectroscopic Research, 1st ed.; Zou, Y., Hutton, R., Eds.; CRC: New York, NY, USA, 2012; pp. 3-20. 